\title{
Phenotypical Variability of the Internal Acoustic Canal in the Middle Cranial Fossa Surgery
}

\author{
Maryna Al-Fauri (Kornieieva) ${ }^{1}$ Paul Kelly $^{1}$ Daniel Lee $^{1} \quad$ Azmy Hadidy $^{2}$ \\ ${ }^{1}$ American University of the Caribbean School of Medicine BV, \\ Cupecoy, Sint Maarten \\ 2 Diagnostic Radiology and Nuclear Medicine, The University of

\begin{abstract}
Address for correspondence Maryna Al-Fauri (Kornieieva), American University of the Caribbean School of Medicine BV, Cupecoy, Sint Maarten (e-mail: malfauri@aucmed.edu; marykorn15@gmail.com).
\end{abstract} Jordan, Amman, Jordan

J Neurol Surg B Skull Base

\begin{abstract}
\section{Keywords}

- cranial index

- anatomical variability

- internal acoustic canal

- temporal bone

- middle cranial fossa

- vestibular schwannoma

Introduction The wide range of anatomical variability of the structures of the middle cranial fossa (MCF) and the lack of reliable surgical landmarks contribute to a high level of complications in the surgical treatment of vestibular schwannomas. We hypothesized that the cranial phenotype influences the shape of the MCF, the orientation of the pyramid of the temporal bone, and the relative topography of the internal acoustic canal (IAC).

Methods The skull base structures were studied on 54 embalmed cadavers and 60 magnetic resonance images of the head and neck by photo modeling, dissection, and three-dimensional analysis techniques. By the value of the cranial index, all specimens were subdivided into dolichocephalic, mesocephalic, and brachycephalic groups for comparison of variables.

Results The length of the superior border of the temporal pyramid (SB), the apex to squama distance, and the width of the MCF all peaked in the brachycephalic group. The value of the angle between the SB and the axis of the acoustic canal varied from 33 to 58 degrees; it peaked in the dolichocephalic group and showed its smaller value in the brachycephalic one. The pyramid to squama angle had reversed distribution and dominated in the brachycephalic group.

Conclusion The cranial phenotype influences the shape of the MCF, temporal pyramid, and IAC. Presented in this article data help specialists operating on the vestibular schwannoma to localize the IAC based on the individual shape of a skull.
\end{abstract}

\section{Introduction}

The middle cranial fossa (MCF) approach is considered the gold standard in the treatment of small- and medium-sized intracanalicular vestibular schwannomas. ${ }^{1-3}$ The wide range of anatomic variability and lack of proper visualization of the internal acoustic meatus from the MCF aspect challenges the treatment method significantly. ${ }^{4}$ Several authors report the insufficient reliability of the existing anatomical landmarks in the $\mathrm{MCF}^{5-7}$ that may cause postoperative complications. ${ }^{8-10}$ Additional research and out-of-the-box solutions in this field are required.

The individual anatomic variability of the shape of the skull has proved its significance in anthropology, forensic medicine, and criminology. ${ }^{11,12}$ In oral and maxillofacial surgery, the craniofacial relations are thoroughly studied as they determine the position of the mandible and type of received

June 29, 2021

accepted after revision

January 28, 2022

accepted manuscript online

March 24, 2022
DOI https://doi.org/

10.1055/a-1786-9026.

ISSN 2193-6331.

\footnotetext{
(C) 2022. The Author(s).

This is an open access article published by Thieme under the terms of the Creative Commons Attribution-NonDerivative-NonCommercial-License, permitting copying and reproduction so long as the original work is given appropriate credit. Contents may not be used for commercial purposes, or adapted, remixed, transformed or built upon. (https://creativecommons.org/ licenses/by-nc-nd/4.0/) Georg Thieme Verlag KG, Rüdigerstraße 14, 70469 Stuttgart, Germany
} 
bite. ${ }^{13}$ Recent craniological studies show that the phenotype is an important factor to consider in neurosurgery as well: it may alter the position of intracranial structures and determine the choice of a surgical approach. ${ }^{14-16}$ The relationship between the value of the cranial index $(\mathrm{CI})$ and morphology of the skull base structures is still unclear and requires additional research.

We built the present study on the assumption that the cranial phenotype does influence the shape of the MCF, the orientation of the pyramid of the temporal bone, shape, and the relative topography of the internal acoustic canal (IAC). Our goal is to study the topography of the abovementioned structures in brachycephalic, mesocephalic, and dolichocephalic subjects and provide surgeons with reliable landmarks.

\section{Materials and Methods}

Fifty-four cadavers and 60 magnetic resonance (MR) images of the head were included in this study: all without known osteological pathology and visible head deformation (52-78 years old, 55 men, 59 women). All body donors were legally competent and had a will in which they agreed to the use of their body for research, study, or teaching purposes; the patients who underwent radiologic examination have signed the written concern. The Institutional Review Board has approved the study.

The dissection took place in the specialized laboratory as a part of the routine education process. Following the craniotomy procedure, the brain (including dura matter and cranial nerves) was removed exposing the structures of the temporal pyramid in the middle and posterior cranial fossae. Then, 26 photos were taken from the skull base with a 15-degree angle difference and uploaded to the PhotoModeler software for three-dimensional (3D) modeling (-Fig. 1). The obtained
3D models underwent scaling and rotation setting and the following measurements were taken digitally:

- The anterolateral and anteroposterior diameters of the skull

- The width and length of the MCF

- The length of the superior border of the pyramid (SB), the width of its base, and the distance from the apex of the pyramid to the temporal squama

- The distance from the upper margins of the porus acusticus to the SB

- The width and height of the internal acoustic meatus in its middle part

- The length (depth) of the IAC was measured manually by a caliper with a scale of $0.01 \mathrm{~mm}$.

To identify the porus acusticus in the MCF, we projected the anterior and posterior margins of the porus acusticus to the SB (-Fig. 2). The following distances were measured on the obtained 3D models:

- Between the apex of the pyramid and the projected anterior margin of the porus acusticus (D1)

- Between the extended anterior and posterior margins of the porus acusticus (D2)

- Between the projected posterior margin of the porus acusticus and the most lateral point of the SB (D3).

On the axial MR images of the head, we have identified the SB and the axis of the IAC and measured the following angles:

- Between the axis of the canal and the SB

- Between the lateral wall of the MCF and the SB (-Fig. 3 ).

To illustrate the challenges faced by MCF surgeons, we simulated the MCF approach on a cadaver. The skin incision

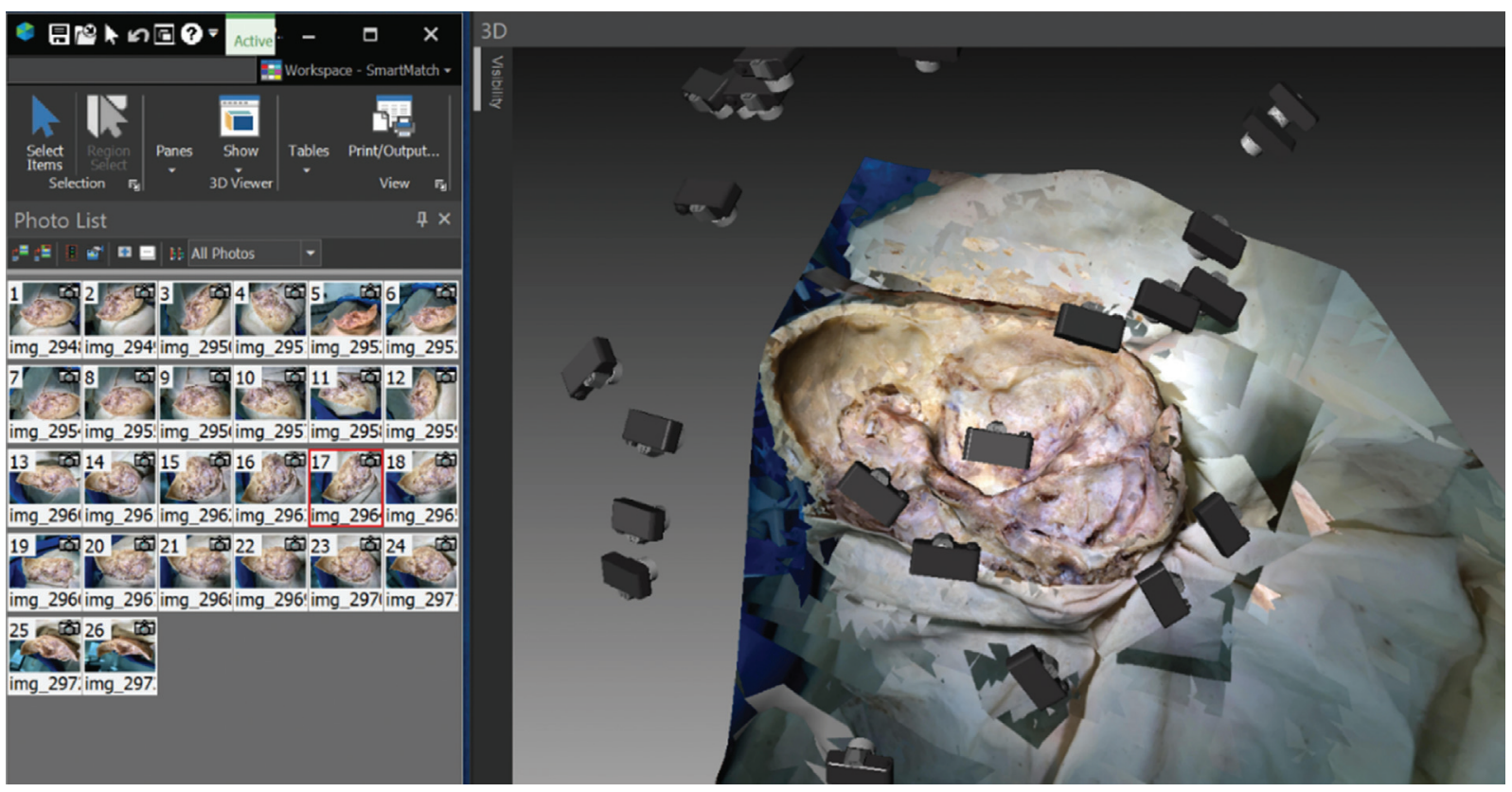

Fig. 1 A screenshot of the three-dimensional (3D) modeling window on the PhotoModeler platform is presented in this picture. The program analyses the light angles and distances between similar points in pictures and creates a digital 3D model of the object. The obtained 3D model is scaled by the largest diameter of the studied object, and the rotation axes are set up manually. The camera underwent preliminary calibration allowing accurate measurements with a residual of less than 3 px (PhotoModeler software, 2021). 


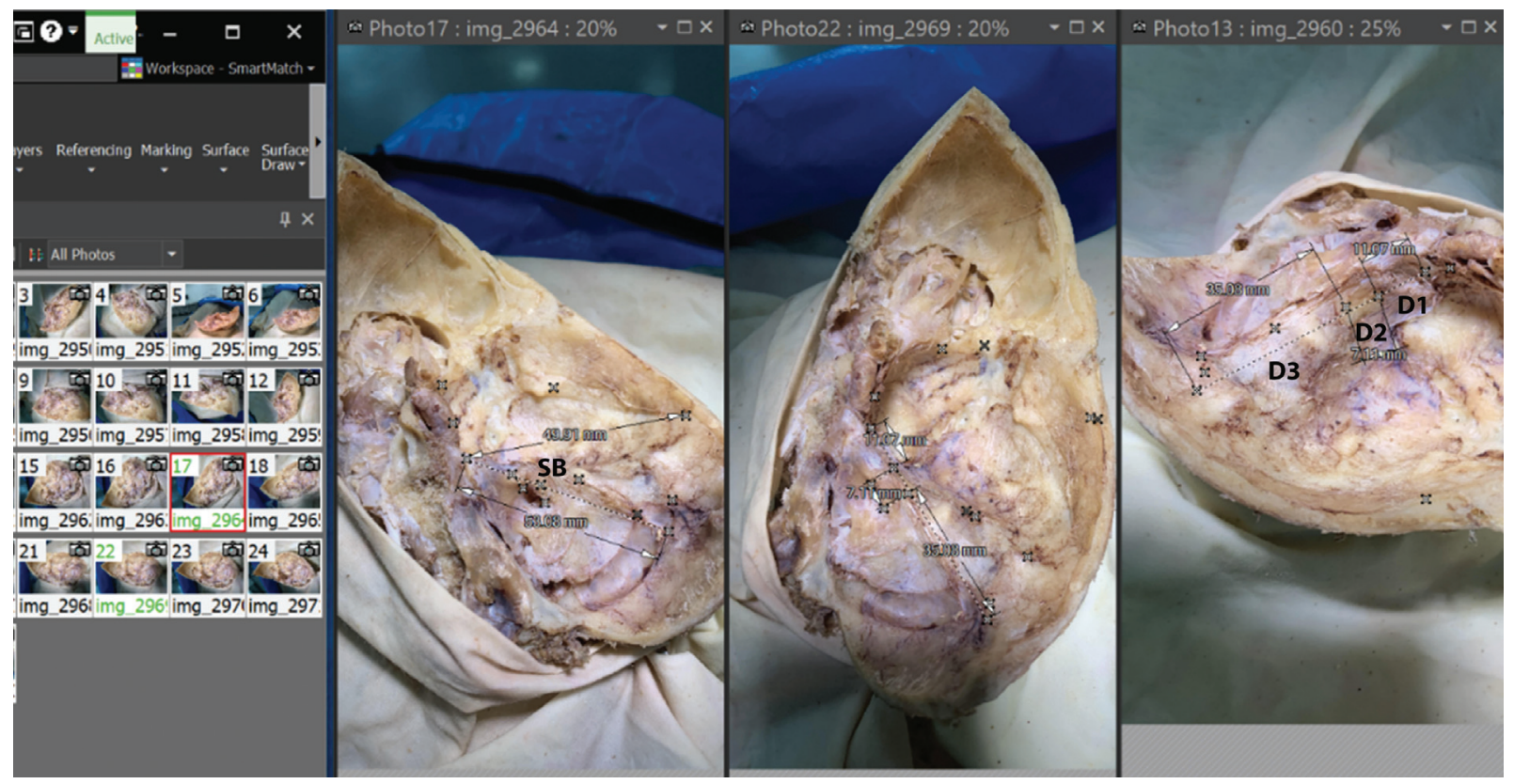

Fig. 2 A screenshot of the "measurements" window of the PhotoModeler platform is presented in this picture. The superior border of the temporal pyramid (SB) is marked along the groove of the superior petrous sinus. The anterior (medial) and posterior (lateral) margins of the porus acusticus are identified and extended up perpendicular to the SB. From the middle cranial fossa view, the following distances are measured: (D1) - between the apex of the pyramid and the projection of the anterior margin of the porus acusticus; (D2)-between the projection points of the anterior and posterior margins of the porus acusticus; and (D3)-from the projection point of the posterior margin of the porus acusticus to the most lateral point of the SB (PhotoModeler software, 2021).
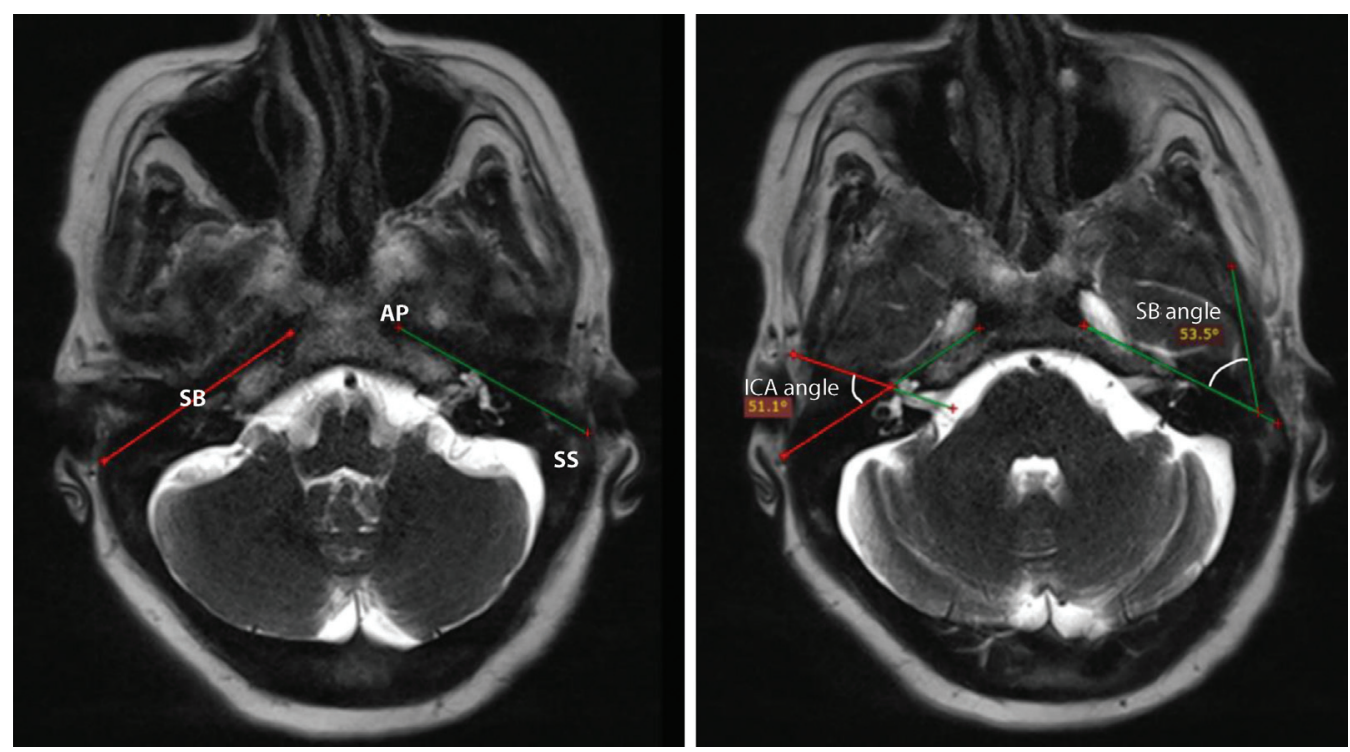

Fig. 3 On the axial magnetic resonance image of the head (T2-weighted), the superior border of the temporal pyramid (SB) was identified as a hypointense longitudinal shadow connecting the apex of the pyramid (AP) with the shadow of the sigmoid sinus (SS). The internal carotid artery that appears at the apex of the temporal pyramid helped demarcate the precise location of the bony apex. The axis of the internal acoustic canal (IAC) was dragged through the center of the canal and extended forward and laterally reaching the lateral wall of the middle cranial fossa. Then, the axis was projected to the same level with the SB, and the angles between the SB and the axis of the IAC angle and between the SB and the temporal squama (SB angle) were measured (RadiAnt software package, 2021).

was placed at the level of the root of the zygomatic arch $1 \mathrm{~cm}$ anterior to the external acoustic meatus to avoid injury of the temporal branch of the facial nerve; then, it was extended upward along the hairline and arched forward $\sim 7 \mathrm{~cm}$ above the zygomatic arch (-Fig. 4A). After the reflection of the scalp flap anteriorly, we incised the temporal fascia and detached the temporalis muscle from the cranium. On the surface of the bone, we marked four bone holes (as close to the posteroinferior margin of the operative wound as possible) and resected 5 to $4 \mathrm{~cm}$ bone flap ( $\boldsymbol{- F i g . ~ 4 B}$ ). Then, we elevated the dura mater from the floor of the MCF and retracted the temporal lobe 18 to $20 \mathrm{~mm}$ anteriorly 

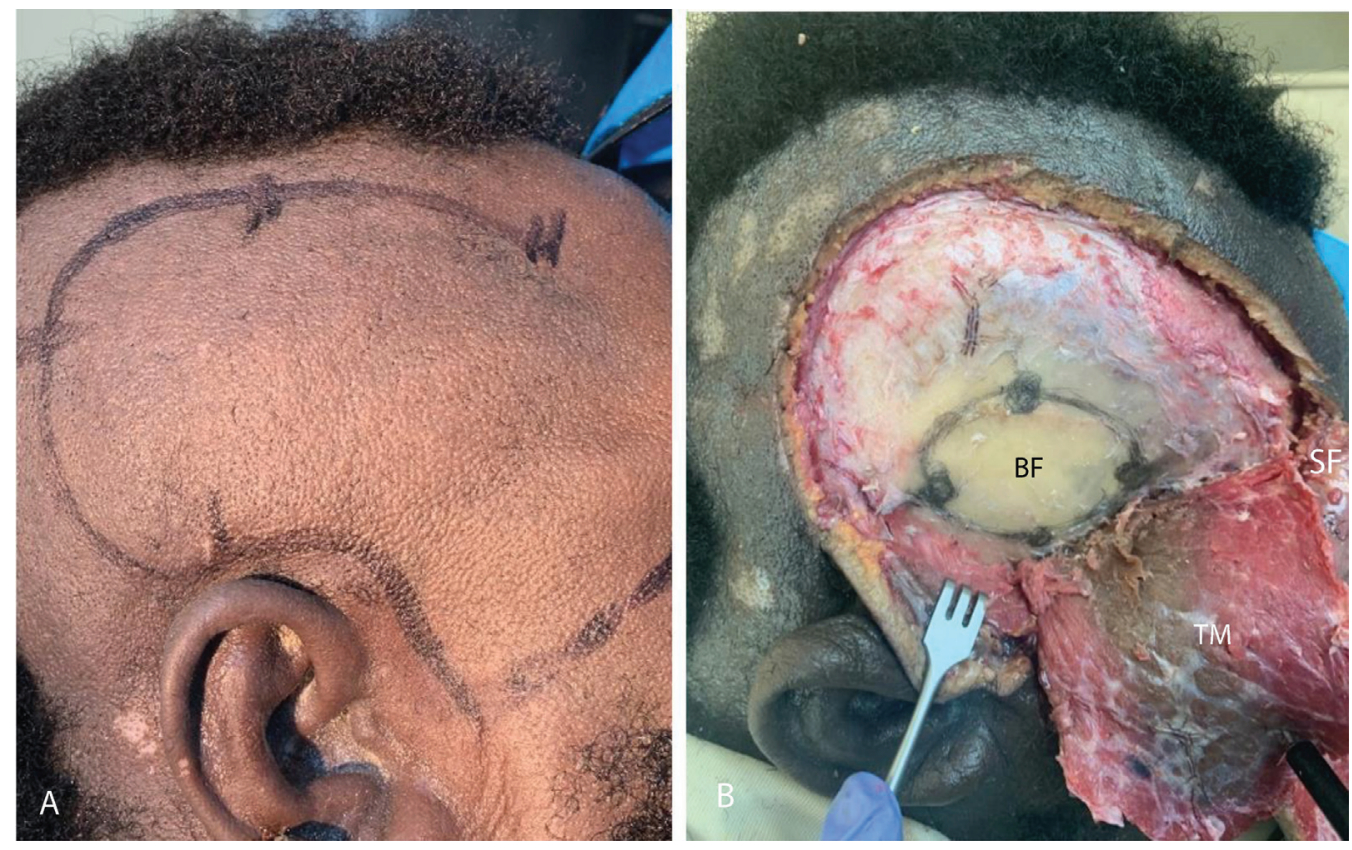

Fig. 4 The image (A) shows the planning of the skin incision for subtemporal craniotomy on a cadaver specimen (male, mesocephalic phenotype). The line of incision begins at the level of the root of the zygomatic arch $1 \mathrm{~cm}$ anterior to the auricle; then, it extends upward along the line of hair growth and arches over the temporal fossa. On the image (B), the skin flap (SF), temporal facial, and temporal muscle (TM) are reflected anteriorly. The 4- to 5-cm bony flap (BF) is marked on the surface of the temporal squama in immediate proximity to the root of the zygomatic arch and the auricle.
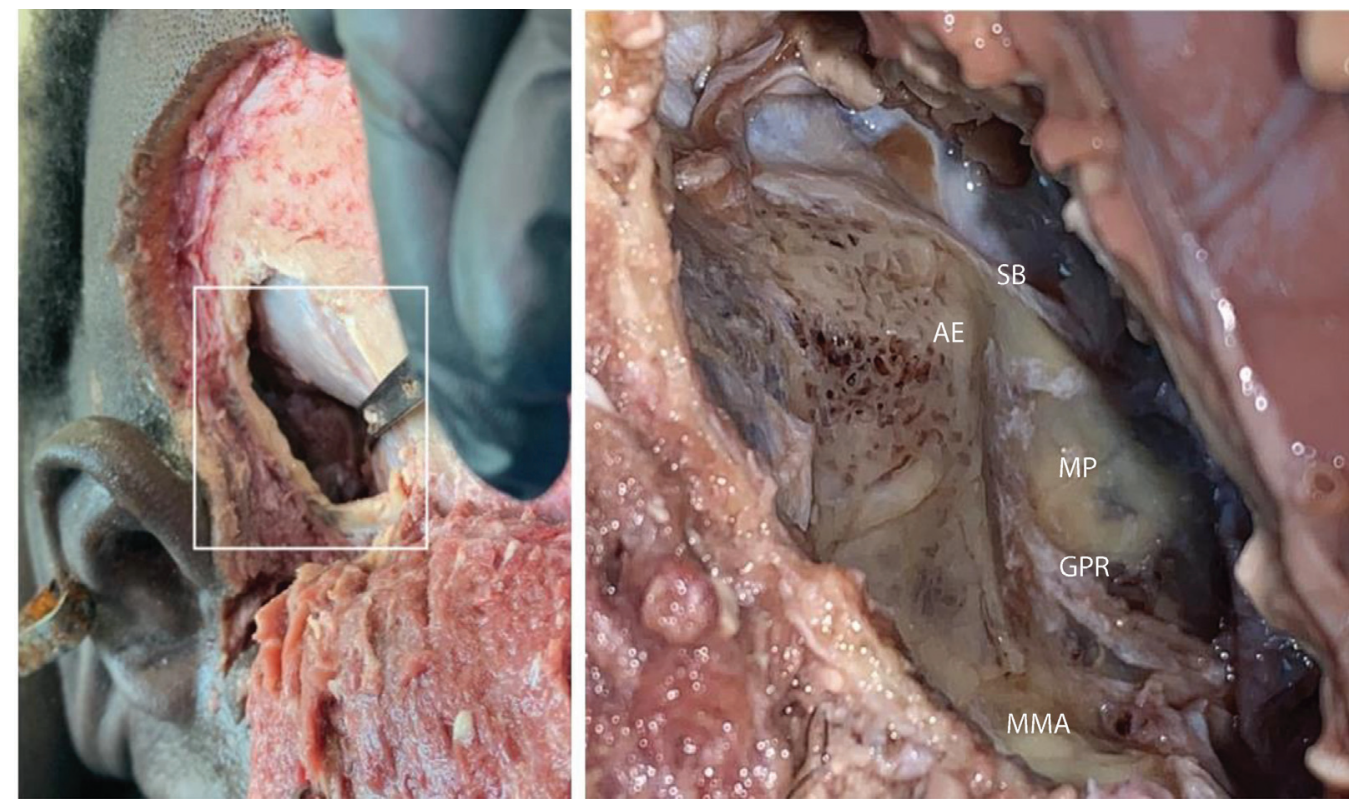

Fig. 5 Surgical view of the right middle cranial fossa reached via the subtemporal approach (simulation on a male cadaver; mesocephalic phenotype, cranial index $=76.4$ ). The dura mater is elevated exposing the anterior surface of the temporal pyramid with the following anatomical landmarks: SB, superior border of the pyramid; AE, arcuate eminence; GPR, greater petrosal nerve; MP, meatal plate; MMA, middle meningeal artery (dissected). The precise localization of the internal acoustic canal, its length, and the distance from the surface of the bone are still unclear at this stage of the procedure. Note: the operative corridor is significantly smaller in females (Maina et al, $2007^{6}$ ).

uncovering the anterior surface of the temporal pyramid and the main anatomic landmarks used in surgery: the arcuate eminence, the ridge of the greater petrosal nerve, and the meatal plate (-Fig. 5). The meatal plate is the part of the temporal bone that roofs the IAC and undergoes drilling in the radical treatment of vestibular schwannomas.
To evaluate the shape of the skull, the laterolateral and anteroposterior diameters of the skull were measured on both wet and radiologic specimens of the skull and axial MR images, as previously described. ${ }^{16,17}$ The $\mathrm{CI}$ was calculated as a percentage ratio of the laterolateral diameter of the skull to the anteroposterior diameter. All specimens were 
subdivided into three groups according to $\mathrm{CI}$ value: dolichocephalic $(\mathrm{Cl}<74.9)$, mesocephalic $(\mathrm{CI}=75-79.9)$, and brachycephalic $(\mathrm{CI}>80)$. The methods of descriptive statistics were used to analyze the average and distribution of the variables in each phenotypical and gender group. Analysis of variance (ANOVA) was employed to verify the significance of differences (SPSS software package, 2020).

\section{Results}

The anteroposterior and laterolateral skull diameters varied significantly with the sex and shape of the head ( - Table $\mathbf{1}$ ). According to the cranial phenotype, $44 \%$ of the cadaver specimens had mecocephalic skulls; $37 \%$ constitute the dolichocephalic group, and 19\% the brachycephalic one. The radiologic cranial groups were equal in number and included 10 men and 10 women each (40 sides per group).
The measurements of the MCF and the pyramid of temporal bone correlated positively with the diameters of the skull (-Table 2). Although the inner diameters of the IAC did not show a strong correlation with the shape of the skull, the orientation of the canal in relation with the SB correlated positively with the anteroposterior and negatively with the laterolateral diameters of the skull with the significance of 0.01 level ( - Table 3 ).

The width of the MCF correlated positively with the distance between the anterior and posterior margins of the porus acusticus projected to the SB (D2), while the length of the MCF showed positive associations with the value of D3

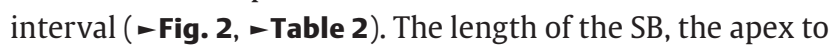
squama distance, and the width of the MCF all peaked in the brachycephalic group. But the width of the base of the pyramid and the length of the IAC were prevailing in the mesocephalic group (-Table $\mathbf{1}$ ).

Table 1 Descriptive statistics of data measured on 3D models of the cadaveric skull bases analyzed by sex and the shape of the skull (mean, \pm SEM [SD], mm)

\begin{tabular}{|c|c|c|c|c|c|c|c|}
\hline Variables & $\begin{array}{l}M \\
n=50\end{array}$ & $\begin{array}{l}F \\
n=58\end{array}$ & $\begin{array}{l}p \text {-Value } \\
\text { by ANOVA }\end{array}$ & $\begin{array}{l}\text { DC } \\
n=40\end{array}$ & $\begin{array}{l}\mathrm{MC} \\
n=48\end{array}$ & $\begin{array}{l}B C \\
n=20\end{array}$ & $\begin{array}{l}p \text {-Value } \\
\text { by ANOVA }\end{array}$ \\
\hline AP & $\begin{array}{l}190.5 \pm 0.26 \\
(19.3)\end{array}$ & $\begin{array}{l}174.1 \pm 0.11 \\
(8.5)\end{array}$ & $<0.001$ & $\begin{array}{l}192.6 \pm 0.34 \\
(21.7)\end{array}$ & $\begin{array}{l}178.3 \pm 0.07 \\
(5.3)\end{array}$ & $\begin{array}{l}169.4 \pm 0.23 \\
(10.3)\end{array}$ & 0.012 \\
\hline $\mathrm{LL}$ & $\begin{array}{l}140.1 \pm 0.08 \\
(5.9)\end{array}$ & $\begin{array}{l}134.2 \pm 0.09 \\
(6.7)\end{array}$ & $<0.001$ & $\begin{array}{l}135.0 \pm 0.13 \\
(7.9)\end{array}$ & $\begin{array}{l}136.6 \pm 0.06 \\
(4.0)\end{array}$ & $\begin{array}{l}142.4 \pm 0.17 \\
(7.9)\end{array}$ & $<0.001$ \\
\hline MCF length & $\begin{array}{l}56.89 \pm 0.59 \\
(4.30)\end{array}$ & $\begin{array}{l}53.01 \pm 0.70 \\
(5.26)\end{array}$ & 0.033 & $\begin{array}{l}55.86 \pm 0.83 \\
(5.23)\end{array}$ & $\begin{array}{l}55.15 \pm 0.77 \\
(5.35)\end{array}$ & $\begin{array}{l}53.20 \pm 1.01 \\
(4.53)\end{array}$ & 0.200 \\
\hline MCF width & $\begin{array}{l}46.02 \pm 0.63 \\
(4.55)\end{array}$ & $\begin{array}{l}43.95 \pm 0.71 \\
(5.34)\end{array}$ & $<0.001$ & $\begin{array}{l}43.87 \pm 0.79 \\
(5.02)\end{array}$ & $\begin{array}{l}45.82 \pm 0.73 \\
(5.11)\end{array}$ & $\begin{array}{l}46.99 \pm 1.08 \\
(4.86)\end{array}$ & 0.272 \\
\hline SB & $\begin{array}{l}53.12 \pm 0.59 \\
(4.30)\end{array}$ & $\begin{array}{l}50.70 \pm 0.62 \\
(4.66)\end{array}$ & 0.007 & $\begin{array}{l}49.16 \pm 0.77 \\
(4.92)\end{array}$ & $\begin{array}{l}51.99 \pm 0.58 \\
(4.08)\end{array}$ & $\begin{array}{l}53.78 \pm 0.99 \\
(4.45)\end{array}$ & $<0.001$ \\
\hline $\mathrm{BP}$ & $\begin{array}{l}27.87 \pm 0.38 \\
(2.78)\end{array}$ & $\begin{array}{l}27.41 \pm 0.37 \\
(2.79)\end{array}$ & 0.398 & $\begin{array}{l}27.22 \pm 0.43 \\
(2.75)\end{array}$ & $\begin{array}{l}28.38 \pm 0.44 \\
(3.06)\end{array}$ & $\begin{array}{l}26.66 \pm 0.32 \\
(1.45)\end{array}$ & 0.031 \\
\hline AS & $\begin{array}{l}51.27 \pm 0.84 \\
(6.06)\end{array}$ & $\begin{array}{l}49.80 \pm 0.65 \\
(4.86)\end{array}$ & 0.166 & $\begin{array}{l}48.14 \pm 0.84 \\
(5.31)\end{array}$ & $\begin{array}{l}49.86 \pm 0.76 \\
(5.28)\end{array}$ & $\begin{array}{l}52.79 \pm 1.35 \\
(6.04)\end{array}$ & 0.116 \\
\hline PA up & $\begin{array}{l}5.98 \pm 0.19 \\
(1.44)\end{array}$ & $\begin{array}{l}6.40 \pm 0.20 \\
(1.52)\end{array}$ & 0.377 & $\begin{array}{l}6.96 \pm 0.21 \\
(1.32)\end{array}$ & $\begin{array}{l}6.60 \pm 0.19 \\
(1.34)\end{array}$ & $\begin{array}{l}5.52 \pm 0.42 \\
(1.88)\end{array}$ & 0.082 \\
\hline D1 & $\begin{array}{l}16.47 \pm 0.37 \\
(2.69)\end{array}$ & $\begin{array}{l}15.91 \pm 0.50 \\
(3.69)\end{array}$ & 0.408 & $\begin{array}{l}14.60 \pm 0.70 \\
(4.45)\end{array}$ & $\begin{array}{l}14.67 \pm 0.34 \\
(2.41)\end{array}$ & $\begin{array}{l}16.66 \pm 0.32 \\
(1.36)\end{array}$ & 0.423 \\
\hline D2 & $\begin{array}{l}7.86 \pm 0.13 \\
(0.94)\end{array}$ & $\begin{array}{l}8.06 \pm 0.19 \\
(1.46)\end{array}$ & 0.003 & $\begin{array}{l}8.42 \pm 0.17 \\
(1.08)\end{array}$ & $\begin{array}{l}8.02 \pm 0.13 \\
(0.92)\end{array}$ & $\begin{array}{l}6.57 \pm 0.31 \\
(1.32)\end{array}$ & 0.429 \\
\hline D3 & $\begin{array}{l}34.87 \pm 0.53 \\
(3.85)\end{array}$ & $\begin{array}{l}32.32 \pm 0.65 \\
(4.80)\end{array}$ & 0.823 & $\begin{array}{l}32.74 \pm 0.94 \\
(5.96)\end{array}$ & $\begin{array}{l}33.55 \pm 0.45 \\
(3.17)\end{array}$ & $\begin{array}{l}34.72 \pm 0.77 \\
(3.29)\end{array}$ & 0.017 \\
\hline IAC length & $\begin{array}{l}11.7 \pm 0.04 \\
(2.9)\end{array}$ & $\begin{array}{l}10.6 \pm 0.20 \\
(1.52)\end{array}$ & 0.088 & $\begin{array}{l}11.2 \pm 0.03 \\
(0.23)\end{array}$ & $\begin{array}{l}11.5 \pm 0.03 \\
(0.21)\end{array}$ & $\begin{array}{l}10.5 \pm 0.08 \\
(0.37)\end{array}$ & 0.324 \\
\hline IAC height & $\begin{array}{l}3.39 \pm 0.10 \\
(0.74)\end{array}$ & $\begin{array}{l}3.16 \pm 0.08 \\
(0.61)\end{array}$ & 0.043 & $\begin{array}{l}3.33 \pm 0.12 \\
(0.73)\end{array}$ & $\begin{array}{l}3.18 \pm 0.09 \\
(0.62)\end{array}$ & $\begin{array}{l}2.40 \pm 0.16 \\
(0.75)\end{array}$ & $<0.001$ \\
\hline IAC width & $\begin{array}{l}5.46 \pm 0.53 \\
(1.39)\end{array}$ & $\begin{array}{l}5.52 \pm 0.17 \\
(1.32)\end{array}$ & 0.141 & $\begin{array}{l}5.63 \pm 0.26 \\
(1.70)\end{array}$ & $\begin{array}{l}5.63 \pm 0.16 \\
(1.10)\end{array}$ & $\begin{array}{l}3.88 \pm 0.19 \\
(0.87)\end{array}$ & 0.075 \\
\hline
\end{tabular}

Abbreviations: ANOVA, analysis of variants; AP, anteroposterior diameter of skull; AS, apex to squama distance; BC, brachycephalic phenotype; BP, width of base of temporal pyramid; D1, distance between the apex of the pyramid and the projected anterior margin of the porus acusticus; D2, between the projected anterior and posterior margins; D3, between the projected posterior margin and the termination of the superior border of the pyramid; DC, dolichocephalic phenotype; IAC, internal acoustic canal; LL, laterolateral diameter of skull; MC, mesocephalic phenotype; MCF middle cranial fossa; PA up, distance between the upper margin of the porus acusticus and the superior border of the temporal pyramid; SB, length of superior border of temporal pyramid; SD, standard deviation; SEM, standard error of mean. 


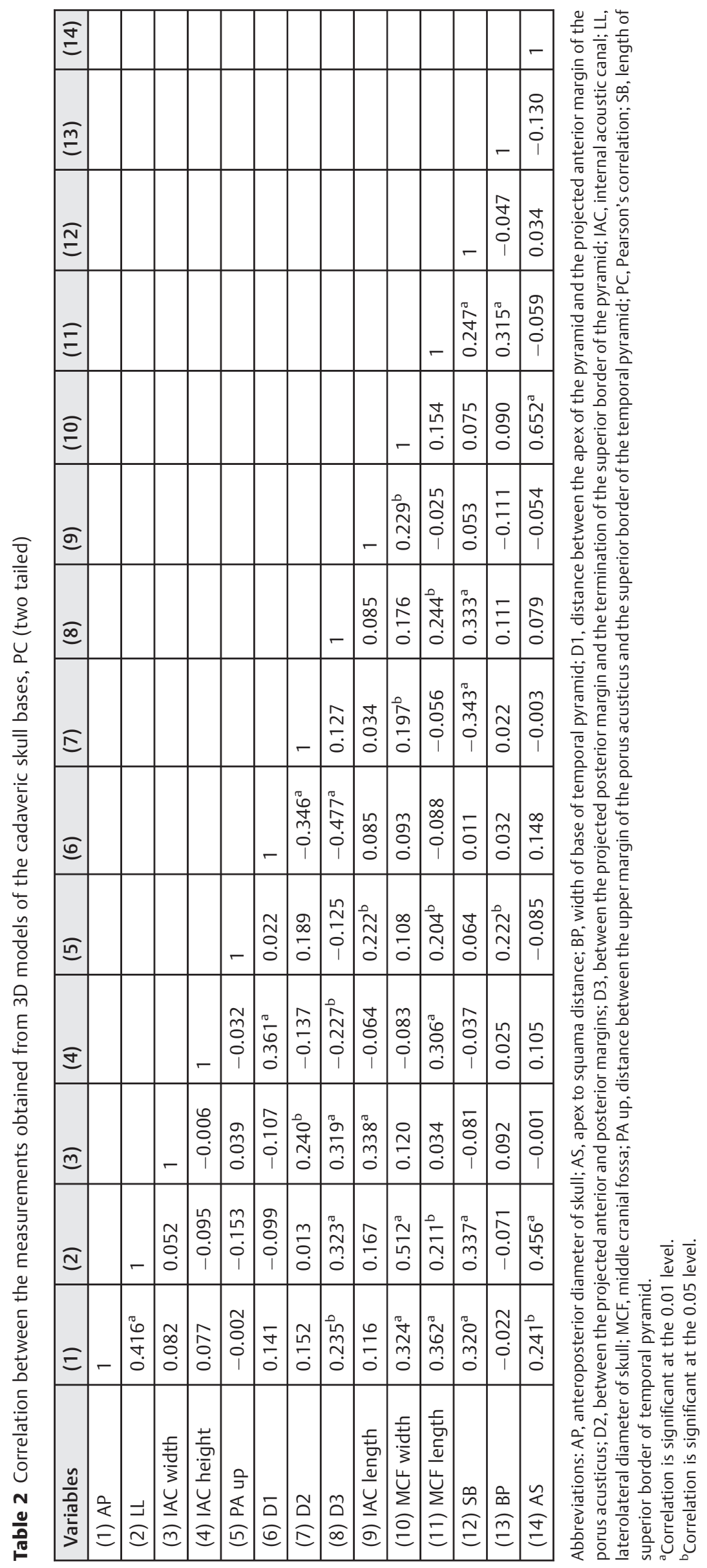


Table 3 Angulation of the temporal pyramid and the internal acoustic canal measured on the magnetic resonance images subject to sex and shape of the skull

\begin{tabular}{|c|c|c|c|c|c|c|}
\hline \multicolumn{7}{|c|}{ Descriptive statistic (mean, \pm SEM [SD], deg) } \\
\hline & $\begin{array}{l}\text { General } \\
n=120\end{array}$ & $\begin{array}{l}\text { Males } \\
n=60\end{array}$ & $\begin{array}{l}\text { Females } \\
n=60\end{array}$ & $\begin{array}{l}\text { DC } \\
n=40\end{array}$ & $\begin{array}{l}M C \\
n=40\end{array}$ & $\begin{array}{l}B C \\
n=40\end{array}$ \\
\hline IAC angle & $44.79 \pm 0.87(7.08)$ & $44.21 \pm 1.35(7.67)$ & $45.33 \pm 1.12(6.55)$ & $51.06 \pm 1.68(7.55)$ & $44.94 \pm 0.78(3.82)$ & $38.92 \pm 0.80(3.78)$ \\
\hline SB angle & $53.03 \pm 0.74(6.02)$ & $54.05 \pm 1.34(7.59)$ & $52.08 \pm 0.67(3.91)$ & $49.70 \pm 1.02(4.59)$ & $53.26 \pm 1.09(5.35)$ & $55.82 \pm 1.39(6.55)$ \\
\hline \multicolumn{7}{|c|}{ Correlation of the IAC and SB angles with the diameters of skull, Pearson's correlation (two tailed) } \\
\hline & AP & $\mathrm{LL}$ & & AP & LL & \\
\hline IAC angle & $0.352^{\mathrm{a}}$ & $-0.521^{\mathrm{a}}$ & SB angle & $-0.553^{a}$ & 0.302 & \\
\hline \multicolumn{7}{|c|}{ ANOVA test results for males and females } \\
\hline Source & \multicolumn{2}{|l|}{ Sum of squares } & df & Mean square & $F$ & Significance \\
\hline \multirow[t]{2}{*}{ IAC angle } & Between groups & 20.782 & 1 & 20.782 & \multirow[t]{2}{*}{0.410} & \multirow[t]{2}{*}{0.426} \\
\hline & Within groups & $3,245.573$ & 58 & 50.712 & & \\
\hline \multirow[t]{2}{*}{ SB angle } & Between groups & 64.229 & 1 & 64.229 & \multirow[t]{2}{*}{1.791} & \multirow[t]{2}{*}{0.184} \\
\hline & Within groups & $2,295.068$ & 58 & 35.860 & & \\
\hline \multicolumn{7}{|c|}{ ANOVA test results for cranial phenotypes } \\
\hline Source & \multicolumn{2}{|l|}{ Sum of squares } & $\mathrm{df}$ & Mean square & $F$ & Significance \\
\hline \multirow[t]{2}{*}{ IAC angle } & Between groups & $1,544.188$ & 2 & 772.094 & \multirow[t]{2}{*}{28.245} & \multirow[t]{2}{*}{$<0.0001$} \\
\hline & Within groups & $1,722.166$ & 57 & 27.336 & & \\
\hline \multirow[t]{2}{*}{ PS angle } & Between groups & 395.261 & 2 & 197.630 & \multirow[t]{2}{*}{6.339} & \multirow[t]{2}{*}{0.003} \\
\hline & Within groups & $1,964.037$ & 57 & 31.175 & & \\
\hline
\end{tabular}

Abbreviations: ANOVA, analysis of variants; BC, brachycephalic phenotype; DC, dolichocephalic phenotype; IAC angle, angle between the axis of the internal acoustic canal and the superior border of the pyramid; MC, mesocephalic phenotype; PS angle, angle between the superior border of the pyramid and the temporal squama.

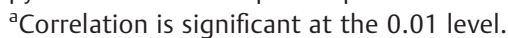

${ }^{\mathrm{b} C o r r e l a t i o n}$ is significant at the 0.05 level.

The mean diameter of the internal acoustic meatus was relatively smaller in the brachiocephalic group. The mean distance from the superior margin of the porus acusticus to the SB was significantly closer to the superior border in the brachycephalic skulls and laid $\sim 2 \mathrm{~mm}$ lower in the dolichocephalic ones revealing strong associations with the cranial phenotype (-Table 1). The table shows the dominance of D1 and D3 distances in the brachycephalic specimens; however, the length between the projected margins of the porus acusticus (D2) peaks in the dolichocephalic group.

The value of the angle between the SB and the axis of the acoustic canal varied from 33 to 58 degrees; it peaked in the dolichocephalic group and showed its smaller value in the brachycephalic one. The pyramid to squama angle had reversed distribution and dominated in the brachycephalic specimens (-Table $\mathbf{3}$ ).

The measurements of the skull, MCF, temporal pyramid, and the distance from the apex to squama were significantly larger in men. The height and length of the IAC showed the same prevalence. However, the D1 distance and the angles between the IAC, SB, and the lateral wall of the MCF showed no correlation with the sex (-Tables 1 and $\mathbf{3}$ ).

The results of the ANOVA test confirm that the abovementioned differences in variables between the cranial phenotypes and sex groups are statistically significant (-Table 1).

\section{Discussion}

We found that the shape of the MCF correlates positively with the laterolateral diameter of the skull. The brachycephalic skulls possessed the larger length of the SB, the distance from the apex of the pyramid to the squama of the temporal bone, and the angle between the pyramid and the lateral wall of the MCF (SB angle). On the contrary, the dolichocephalic skulls had a $4.65-\mathrm{mm}$ shorter apex to squama distance and $\sim 20$ degrees reduced pyramid to the lateral wall angle. We would like to emphasize that the angle between the IAC and the SB (IAC angle) showed reversed distribution: it was as twice as larger in the dolichocephalic specimens compared with the brachycephalic ones (-Figs. 6-8). These data show a clear pattern of distribution of the variables between the cranial phenotypes and can help systemize the wide range of variability of the structures of the skull base. The findings on the shape of the MCF, degree of inclination of the pyramid, and topography of the IAC in different cranial phenotypes are novel.

According to our observations, the SB is well visible in the operative wound and may be used for identification of the IAC in the MCF surgery. The D3 distance shows the precise localization of the origin of the IAC. The knowledge of the specific angulation of the IAC in different cranial phenotypes may now be applied to project the canal to the anterior 

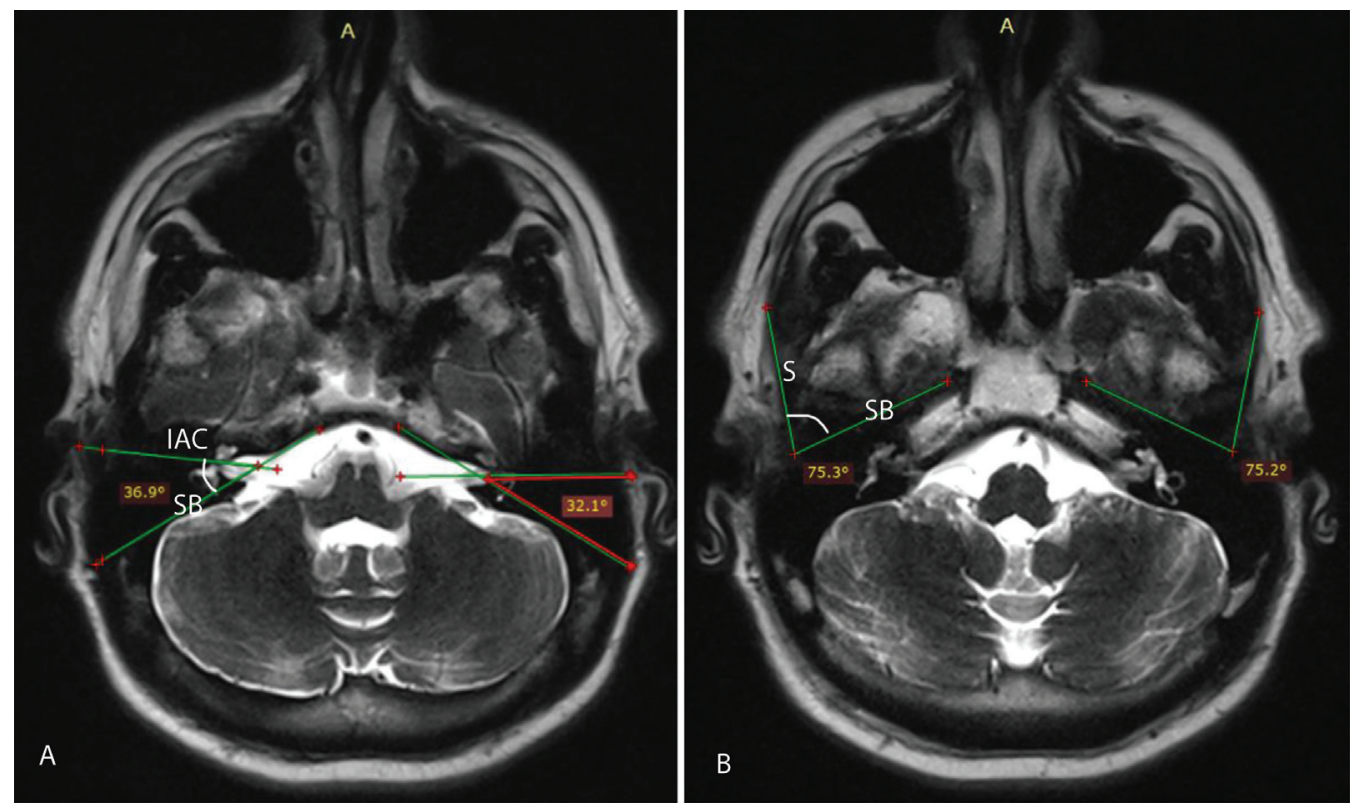

Fig. 6 The axial magnetic resonance image of the head shows: (A) relatively small angle between the axis of the internal acoustic canal (IAC) and the superior border of the temporal pyramid (SB); (B) relatively large angle between the lateral wall of the middle cranial fossa (squama, S) and the SB. The cranial index of this patient is equal to 86.4 (brachycephalic phenotype).
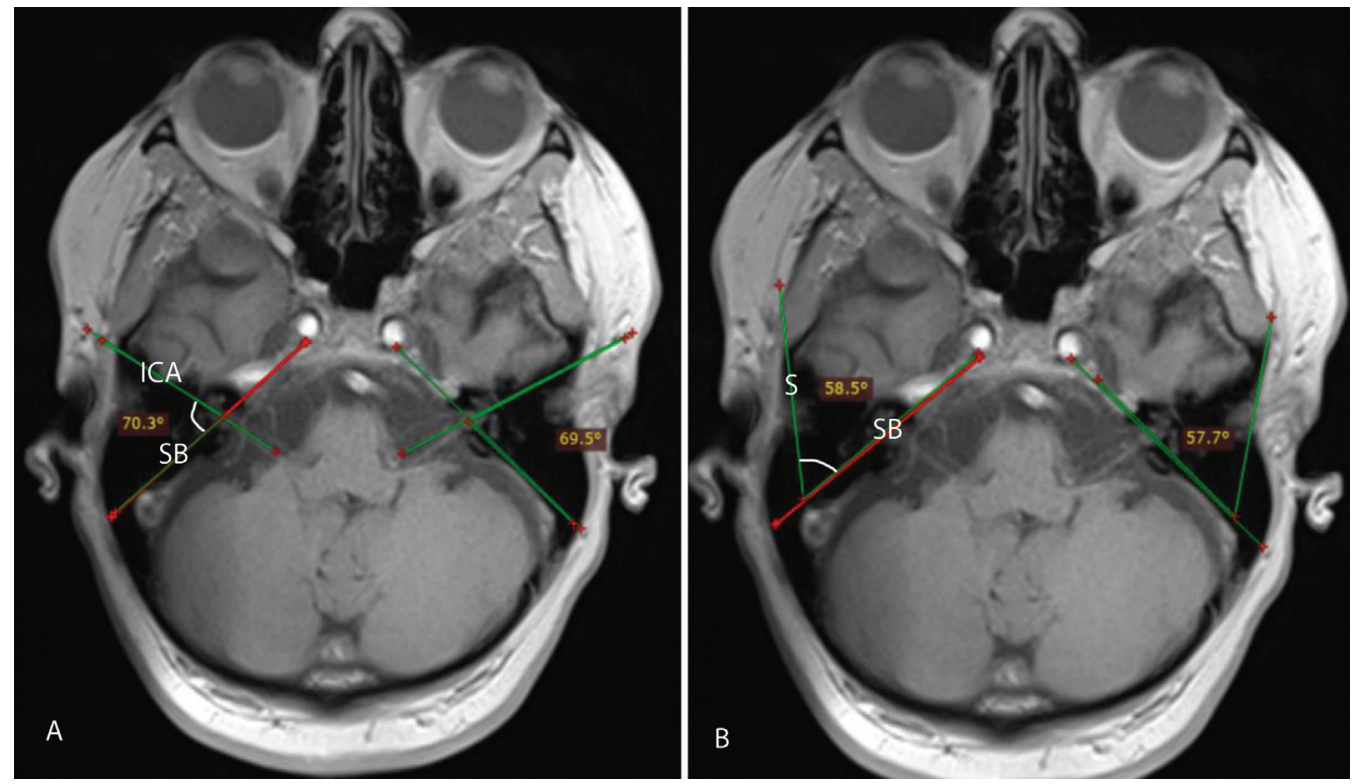

Fig. 7 The axial magnetic resonance image of the head shows: (A) relatively large angle between the axis of the internal acoustic canal (IAC) and the superior border of the temporal pyramid (SB); (B) relatively small angle between the lateral wall of the middle cranial fossa (squama, S) and the SB. The cranial index of this patient is equal to 72.3 (dolichocephalic phenotype).

surface of the temporal pyramid ( - Fig. 8). Comparing the value of the D3 distance in the brachycephalic and dolichocephalic groups, we have found that the posterior wall of the porus acusticus is located $1.98 \mathrm{~mm}$ further from the squama, and $1.44 \mathrm{~mm}$ closer to the SB in the specimens with wider skulls (-Table 1). These small differences may require extended drilling in mesocephalic and dolichocephalic patients that can influence the size of the removable bone significantly. Although the structures of the skull base were all relatively larger in males, the angulation of the internal acoustic meatus and the temporal pyramid showed no sexual dysmorphism among the studied groups. The studied variables showed the same pattern of distribution between the cranial phenotypes in males and females.

The phenotypical features of the MCF and skull base, in general, are poorly addressed in the literature. Introduced by Retzius (1840) and modified by Morrison and King (1973) classification of the shape of the skull subdivided all individuals into three phenotypical groups with wide (brachycephalic), narrow (dolichocephalic), or normal (mesocephalic) shapes of the skull. ${ }^{17-19}$ The relationship between the value of the $\mathrm{Cl}$ and morphology of the skull base structures is still 

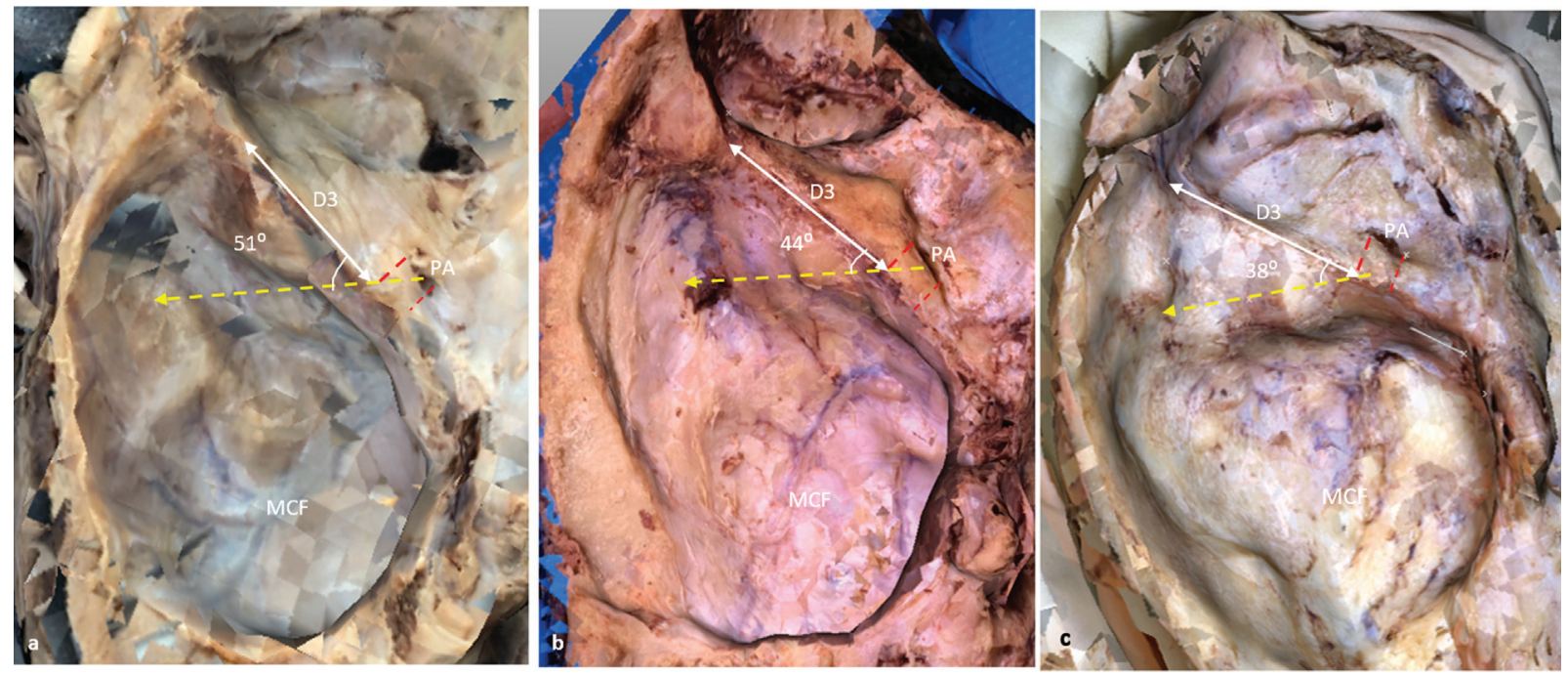

Fig. 8 The phenotypical variability of the middle cranial fossa (MCF), the orientation of the pyramid of the temporal bone, and orientation of the internal acoustic canal (IAC) are demonstrated on three-dimensional (3D) models of cadaveric skull bases with cranial indexes $70.67 \%$ (a), $75.10 \%$ (b), and $85.23 \%$ (c): dolichocephalic, mesocephalic, and brachycephalic specimens, respectively. The distance from the temporal squama to the projection point of the lateral border of the porus acusticus (PA) along the superior border of the pyramid (D3) increases with the laterolateral diameter of the skull. The angle between the superior border of the pyramid and the axis of the IAC (yellow arrow) is significantly large in specimens with narrow skulls. The 3D modeling technique was used to visualize the data (PhotoModeler software, 2021).

unclear till now. Meneses et al (2004) are the first authors who proposed to consider the cranial phenotype in choosing between the personal, subtemporal, presigmoid, and retrosigmoid surgical approaches to the temporal pyramid. They compared the distance between the outer table of the skull and the apex of the temporal pyramid on the computed tomography images of the brachycephalic, mesocephalic, and dolichocephalic patients. The authors described the peculiarities of the brachycephalic skull base but did not specify how exactly this phenotype shapes the bony structures of the MCF that could be important for surgeries in this area. $^{16}$

The MCF approach provides extradural access to the temporal pyramid via a subtemporal route. First introduced by the William House in 1960, this approach remains essential in hearing preserving operations on small-sized intracanalicular vestibular schwannomas. The poor visualization of the IAC and necessary retraction of the temporal lobe are the main drawbacks of this method. ${ }^{10}$ The arcuate eminence located on the anterior surface of the temporal pyramid is the most mentioned anatomical landmark in the $\mathrm{MCF}^{20}$ Originally proposed by Garcia-Ibanex and Garcia-Ibanez (1980), the bisection of the angle formed by the greater petrosal nerve and the arcuate eminence is widely used in localizing the IAC nowadays. ${ }^{21}$ In recent multidisciplinary research, Maina et al (2007) have re-evaluated this angle and confirmed its relative consistency, although the observed value of the angle varied from 139 to 105 degrees among the specimens ( $122 \pm 16.65$ degrees). The authors emphasized that the extreme anatomic variability of the temporal bone negatively influences the appearance of the MCF in surgeries and complicates the recognition of the key anatomical landmarks.

The arcuate eminence is an unreliable surgical landmark as its nature and consistency are often debated by authors: It may reflect the relief of the underlying temporal air cells, may mirror the overlying third sulcus of the temporal lobe of the brain, or may overlay the superior semicircular canal as expected. ${ }^{22,23}$ The eminence is absent in $15 \%$ of cases, is pneumatized in $46 \%$, and only in $37 \%$, it overlies the superior semicircular canal. ${ }^{5,6}$ In most specimens, the superior semicircular canal is located medial to the eminence under the lateral part of the meatal plate and is vulnerable in the procedures on the IAC. ${ }^{5}$ Accidental opening of the inner ear during the surgery jeopardizes its function and often leads to hearing loss even after intense sealing of the defect. ${ }^{6,24}$ High variability and inconsistency of the arcuate eminence limits its reliability as a surgical landmark in hearing preserving operations on the inner ear.

The lack of key surgical landmarks in the MCF surgery inspired research in human morphology. In a study on 40 dry skulls, Peris-Celda et al (2018) evaluated the angle between the groove of the greater petrosal nerve and the anteromedial and posterolateral walls of the IAC as 39 degrees (2060 degrees) and 78.6 degrees (45-90 degrees), respectively. The authors projected the axes of the internal acoustic meatus to the root of the zygomatic arch and to the midpoint of the external acoustic meatus advising to use of these landmarks in surgery planning. ${ }^{7}$ The reported wide range of variability, however, diminishes the practical implementation of the data. Farahani et al (2007) studied the local morphology of the internal acoustic meatus on 14 Iranian 
temporal bones extracted from male cadavers. ${ }^{4}$ The data presented in their research approximate the width, height, and length of the IAC in our brachycephalic group. We can assume the dominance of the laterolateral diameter of the skulls in the Iranian population. In the present research, we analyzed the variability of the internal acoustic meatus, pyramid of the temporal bone, and the variability of the MCF in both males and females. Although the relative size of the skull base structures is prevailing in males, the distribution of the variables by the cranial phenotype showed an identical pattern.

\section{Limitations of This Study}

1. The prevalence of female cadavers in the brachycephalic group could affect the overage of the results in this group; especially, the local characteristics of the IAC and the distance from the porus acusticus to the SB may be affected by this fact due to low correlation with the diameters of the skull. Additional analyses of the data in the dolichocephalic, mesocephalic, and brachycephalic females revealed the same patterns of distribution of the variables.

2. The specimens included in this research represent multiple populations: we studied Caucasian cadavers $(n=54)$ and the MR images of Arabic patients $(n=60)$. To compensate for possible phenotypical differences, we have selected an equal number of dolichocephalic, mesocephalic, and brachycephalic patients for the analysis of the skull base images.

3. The larger sample size is advised to be considered in future studies.

\section{Implications and Future Research}

The morphological data and the modeling technique presented in this article illustrate the possibilities of the clinical application of cranial morphology. Knowledge of the patterns of distribution of the variables by the type of skull allows us to classify the variability of the skull base structures efficiently. In the present study, we focused our attention on the phenotypical variability of the internal acoustic meatus, the temporal pyramid, and the MCF; the variability of the anterior and posterior cranial fossae and the midline structures of the skull base are the potential subjects for the future studies.

\section{Conclusion}

The cranial phenotype shapes the MCF, the temporal pyramid, and the IAC. The parameters of the MCF and the length of the temporal pyramid are larger in the brachycephalic skulls. The SB angles from the lateral wall of the MCF and the axis of the IAC in a specific pattern reflecting the shape of the skull. Despite the relatively larger values in males, the distribution of the studied variables by the cranial phenotype showed no sexual dysmorphism. The SB is a reliable anatomical landmark that may be used for the prediction of the localization of the internal acoustic meatus in the MCF.
The data presented in this article could help in the preliminary evaluation of the patients and individual planning of surgeries on the internal acoustic meatus.

\section{Video 1}

Online content including video sequences viewable at: https://www.thieme-connect.com/products/ ejournals/html/10.1055/a-1786-9026.

\section{Conflict of Interest}

None declared.

\section{References}

1 Myrseth E, Pedersen PH, Møller P, Lund-Johansen M. Treatment of vestibular schwannomas. Why, when and how? Acta Neurochir (Wien) 2007;149(07):647-660, discussion 660

2 Gonzalez F, Ferreira M, Zabramski J, Spetzler R, Deshmukh P. The middle fossa approach. Barrow Quarterly 2000;16(04):67-85

3 Staecker H, Nadol JB Jr, Ojeman R, Ronner S, McKenna MJ. Hearing preservation in acoustic neuroma surgery: middle fossa versus retrosigmoid approach. Am J Otol 2000;21(03):399-404

4 Farahani R, Nooranipour M, Nikakhtar K. Anthropometry of internal acoustic meatus. Int J Morphol 2007;5(04):861-865

5 Faure A, Masse H, Gayet-Delacroix M, et al. What is the arcuate eminence? Surg Radiol Anat 2003;25(02):99-104

6 Maina R, Ducati A, Lanzino G. The middle cranial fossa: morphometric study and surgical considerations. Skull Base 2007;17(06): 395-403

7 Peris-Celda M, Perry A, Carlstrom LP, Graffeo CS, Driscoll CLW, Link MJ. Key anatomical landmarks for middle fossa surgery: a surgical anatomy study. J Neurosurg 2018;131:1-10

8 Wigand ME, Haid T, Berg M. The enlarged middle cranial fossa approach for surgery of the temporal bone and of the cerebellopontine angle. Arch Otorhinolaryngol 1989;246(05):299-302

9 Mahboubi H, Ahmed OH, Yau AY, Ahmed YC, Djalilian HR. Complications of surgery for sporadic vestibular schwannoma. Otolaryngol Head Neck Surg 2014;150(02):275-281

10 Betka J, Zvěřina E, Balogová Z, et al. Complications of microsurgery of vestibular schwannoma. BioMed Res Int 2014;2014:315952

11 Kavitha L, Karthik K. Comparison of cephalometric norms of Caucasians and non-Caucasians: a forensic aid in ethnic determination. J Forensic Dent Sci 2012;4(01):53-55

12 Mesejo P, Marto R, Ibáñez Ó, Novo J, Ortega M. A survey on artificial intelligence techniques for biomedical image analysis in skeleton-based forensic human identification. Appl Sci (Basel) 2020;10(14):4703

13 Chin A, Perry S, Liao C, Yang Y. The relationship between the cranial base and jaw base in a Chinese population. Head Face Med 2014;10:31

14 Kornieieva M, Hadidy A, Zhuravlova I. Variability of the middle meningeal artery subject to the shape of skull. J Neurol Surg B Skull Base 2015;76(06):451-458

15 Kornieieva M, Zhuravlova I, Hadidy A. Stereotactic characteristics of the thalamus subject to shape of the skull: an MRI study. Open Acc Res Anatomy 2017;1(01):504

16 Meneses MS, Moreira AL, Bordignon KC, Pedrozo AA, Ramina R Nikoski JG. Surgical approaches to the petrous apex: distances and relations with cranial morphology. Skull Base 2004;14(01):9-19, discussion 19-20

17 Senol R, Safak N, Yucel A. Anthropometric evaluation of cranial indexes. International Journal of Contemporary Medical Research 2019;6(10):1-4 
18 Morrison AW, King TT. Experiences with a translabyrinthinetranstentorial approach to the cerebellopontine angle. Technical note. J Neurosurg 1973;38(03):382-390

19 Allanson JE, Cunniff C, Hoyme HE, McGaughran J, Muenke M, Neri G. Elements of morphology: standard terminology for the head and face. Am J Med Genet A 2009;149A(01):6-28

20 Rosahl S, Eßer D. Chirurgische Techniken zur Behandlung des Vestibularisschwannoms. HNO 2017;65(05):395-403
21 Garcia-Ibanez E, Garcia-Ibanez JL. Middle fossa vestibular neurectomy: a report of 373 cases. Otolaryngol Head Neck Surg 1980; 88(04):486-490

22 Hovelacque A. Oste’ologie II, Cra^ ne-Face. Paris: Douin; 1934:65-74

23 Paturet G. Traite' d'anatomie humaine. Paris: Masson; 1951:130

24 Schick B, Dlugaiczyk J. Surgery of the ear and the lateral skull base: pitfalls and complications. GMS Curr Top Otorhinolaryngol Head Neck Surg 2013;12:Doc05 